\title{
MAGNESIUM PROTECTS IN EPISODES OF CRITICAL PERFUSION AFTER ANEURYSMAL SAH
}

\begin{abstract}
Background: To analyze whether magnesium has a neuroprotective effect during episodes that indicate a critical brain perfusion after aneurysmal subarachnoid hemorrhage (SAH)

Methods: 107 patients with aSAH were randomized to continuously receive intravenous magnesium sulfate with target serum levels of $2.0-2.5 \mathrm{mmol} / \mathrm{l}(\mathrm{n}=54)$ or isotonic saline $(n=53)$. Neurological examination and transcranial Doppler sonography (TCD) were performed daily, Perfusion-CT (PCT) was acquired in 3-day intervals, angiography in case of suspected vasospasm. The primary endpoint was the development of secondary infarction following episodes of delayed ischemic neurological deficit (DIND), elevated mean flow velocity (MFV) in TCD or pathological findings in PCT.

Results: In the magnesium group, 9 episodes of DIND were registered, none was followed by secondary infarction In the control group, 23 episodes of DIND were registered, 9 were followed by secondary infarction $(p<0.05)$. In the magnesium group, 114 TCD-measurements showed an elevated MFV(> $140 \mathrm{~cm} / \mathrm{s}$ ). 7 were followed by new infarction. In control patients, 135 measurements showed elevated MFV, 32 were followed by new infarction ( $p$ < 0.05). 10 of 117 abnormal PCT-findings were followed by new infarction, compared to 30 of 122 in the controlgroup $(\mathrm{p}<0.05)$.

Conclusion: DIND, elevated MFV in TCD and abnormal PCT are findings which are associated with an increased risk to develop delayed secondary infarction. The results of this analysis suggest that magnesium-treatment may reduce the risk to develop infarction in a state of critical brain perfusion.
\end{abstract}

Keywords

•subarachnoid hemorrhage $\cdot$ magnesium $\cdot$ neuroprotection $\cdot$ delayed cerebral infarction

\section{Introduction}

The data on beneficial effects of magnesiumtreatment in patients who suffered aneurysmal subarachnoid hemorrhage ( $\mathrm{SAH})$ is conflicting. Experimental results in cerebral ischemia [1-4] and early clinical data in stroke patients $[5$, 6] supported the idea that magnesium may act as a neuroprotective agent in cerebral ischemia and $\mathrm{SAH}$. In the last two decades, several clinical studies have shown beneficial effects of magnesium in SAH [7-14]. However, two large multicenter trials failed to confirm a reduced incidence of delayed cerebral ischemia and an improvement of clinical recovery by intravenous administration of magnesium sulfate $[15,16]$ and caused some disillusionment. However, the results of these two large studies may have been influenced by the co-medication. In both trials nimodipine was co-administered as a standard medication to magnesium-treated patients as well as to patients of the control-groups. Similar to nimodipine, magnesium predominantly acts as a calcium antagonist. This co-treatment resembles a combination therapy consisting of two similarly acting substances which is, from a pharmacological point of view, unlikely to exert synergistic effects. From the database of a clinical trial, which we previously reported on [14], we conducted this analysis focusing on the potential neuroprotective effects of continuous highdose administration of magnesium sulfate during episodes of neurological deterioration, arterial vessel narrowing, or abnormalities in perfusion imaging suggesting a critical brain perfusion.
Ekkehard Kunze

Nadine Lilla,

Christian Stetter

Ralf-Ingo Ernestus,

Thomas Westermaier*

Department of Neurosurgery, University Hospital Wuerzburg, Josef-Schneider-Str. 11, 97080 Wuerzburg, Germany

Received 20 October 2017 accepted 20 February 2018

\section{Materials and Methods}

The study was approved by the local ethics committee. Informed consent was obtained from the patient or from a permanent or temporary legal guardian. This is a posthoc analysis from a randomized clinical trial comparing the effects of intravenous magnesium sulfate versus control in patients after aneurysmal SAH [14]. For this purpose, critical events in terms of delayed ischemic neurological deterioration (DIND), angiographic delayed vasospasm, abnormal findings in Perfusion-CT (PCT) and elevated mean flow velocities (MFV) in transcranial Doppler sonography (TCD) were analyzed. While a patient-based analysis has been published previously [14], this is an event-based analysis investigating whether patients in the

*E-mail: Westermaie_T@ukw.de

(cc))BY-NC-ND $\odot 2018$ Ekkehard Kunze et al., published by De Gruyter.

This work is licensed under the Creative Commons Attribution-NonCommercial-NoDerivs 4.0 License. 
magnesium or control group, respectively, developed secondary infarction after these episodes of critical brain perfusion or not.

\section{Inclusion- and exclusion-criteria}

Patients were included if they had suffered aneurysmal SAH within 96 hours before admission and no history of prior bleeding. In- and exclusion criteria have previously been described in detail [14]. All patients were admitted to the neurosurgical intensive care unit of a university hospital. All patients underwent early digital subtraction angiography (DSA) and early endovascular coiling or microsurgical clipping of the ruptured aneurysm within 48 hours after $\mathrm{SAH}$.

\section{Standard management}

Clinical assessment included the Glasgow Coma Scale (GCS) score, World Federation of Neurological Societies (WFNS) score and the Hunt/Hess score. Patients were intubated and mechanically ventilated if their GCS score was below 9 points. An external ventricular drainage was implanted if there were signs of hydrocephalus in CT-scans. Care was taken that mean arterial blood pressure did not fall below $80 \mathrm{mmHg}$ in order to prevent episodes of hypotension. Substances used included Ringer's solution, albumin and hydroxyethyl starch (HES 6\%) and catecholamines [17]. In case of delayed ischemic neurological deterioration (DIND), elevated mean flow velocities (MFV) in transcranial Doppler sonography (TCD) or signs of perfusion deficits in Perfusion-CT (PCT) maps, patients received hyperdynamic therapy with an optimization of hematocrit (30-35\%), central venous pressure $(10-12 \mathrm{mmHg})$ and induced hypertension.

\section{Randomization and Magnesium dosage}

Patients included into the study were randomized to either receive intravenous magnesium sulfate or serve as controls after $\mathrm{SAH}$ was diagnosed by $\mathrm{CT}$ or lumbar puncture and an aneurysm was demonstrated either by digital subtraction angiography (DSA) or CTAngiography (CTA). The latest time of occlusion was 96 hours after $\mathrm{SAH}$. In the magnesium group, a loading dose of $16 \mathrm{mmol} \mathrm{MgSO}_{4}$ over half an hour was administered and followed by a continuous infusion of $8 \mathrm{mmol} / \mathrm{h}$. In the following days, the infusion speed was adjusted according to magnesium serum levels in order to keep the latter at $2.0-2.5 \mathrm{mmol} / \mathrm{l}$. In the control group, an equal volume of saline was administered. Intravenous magnesium was discontinued at day 10 if there were no signs of clinical deterioration or ultrasonographic vasospasm as measured by TCD and if PCT maps did not show any abnormal patterns. In case of clinical vasospasm, elevated MFV in TCD (over $140 \mathrm{~cm} / \mathrm{s}$ ) or abnormal PCT maps, intravenous magnesium was continued until these findings had normalized. Independent of the study procedures, patients were dismissed or transferred to rehabilitation units if their clinical condition was stable and no more danger for secondary ischemic deterioration was believed to be present.

\section{Assessment of study parameters:}

Neurological assessment was conducted three times a day following a standard examination protocol including the GCS, deficits of awareness (person, place, time, situation) and cranial nerves, motor, sensory and coordination deficits of the upper and lower extremities, visual field defects, and speech abnormalities. DIND was defined as a secondary neurological deterioration in the absence of another cause.

A TCD examination was conducted once a day and included the middle and anterior cerebral arteries and internal carotid artery (MCA, ACA, ICA) and the basilar artery. "Ultrasonographic vasospasm" was defined as a MFV $>140 \mathrm{~cm} / \mathrm{s}$ in the anterior circulation and $>$ $90 \mathrm{~cm} / \mathrm{s}$ in the basilar artery.

A two-slice PCT was obtained after native CT in 3-day intervals (Somatom Plus 4 Volume Zoom, Siemens, Erlangen, Germany) For PCT analysis, a commercially available software was used (Perfusion CT, Siemens). Color maps were visually assessed for side asymmetries or clear bilateral defects indicating a decrease in Cerebral Blood Flow (CBF) or Cerebral Blood Volume (CBV), or an increase in Time-To-Peak (TTP) [18]. All study parameters were assessed by personnel not aware of the patient's study allocation.

In case DIND, elevated MFV in TCD or new deficits in PCT, patients received DSA. Angiographic vasospasm was defined as a reduction of the vessel diameter of more than $50 \%$. In this case, the spasm was treated endovascularly by a balloon catheter or - if not accessible - by a local infusion of nimodipine in a dose of $2-4 \mathrm{mg} / \mathrm{h}$ for $30-60$ minutes.

\section{Target parameters}

The target parameter was secondary infarction on native $\mathrm{CT}$ within the following three days after episodes that suggest critical brain perfusion:

1. An episode of DIND,

2. Angiographic vasospasm,

3. Elevated flow velocities in TCD (MFV > 140 $\mathrm{cm} / \mathrm{s}$ ) and

4. Pathological findings in PCT.

CT-scans were analyzed for new hypodensities. Secondary infarction on plain CT-scans were defined as described by von Kummer et al. [19].

\section{Data analysis}

A Fisher exact test was used to analyze incidences. An ROC analysis was performed for trancranial Doppler values to determine the cut-off limit for the value "ultrasonographic vasospasm". This analysis confirmed the inflection point of the ROC curve to be at $140 \mathrm{~cm} / \mathrm{s}$. Statistical analysis was performed using GraphPad Prism 4 Statistical Software (GraphPad Software, San Diego, CA). Differences were considered significant at $p<0.05$. Values are given as mean \pm standard deviation for parametric data. For non-parametric data, median values (and mean values) are given.

\section{Results}

\section{Patient characteristics}

107 patients were included in the study (66 female, 41 male). 54 patients were assigned to receive magnesium, 53 to the control group. The mean age was $50 \pm 12$ years in the magnesium group and $52 \pm 13$ years in the control group ( $p$ $=0.15$ ). The median WFNS score was 3 (mean $2.63 \pm 1.61)$ in the magnesium group and 2 (mean $2.46 \pm 1.64$ ) in the control group. The median Hunt/Hess Score was 3 in both groups (mean $2.88 \pm 1.24$ in the magnesium group and 
$2.66 \pm 1.30$ in the control group). The median Fisher Score was 3 in both groups. Patients in the magnesium group were hospitalized 21,9 \pm 7.8 days, patients in the control group were hospitalized $20.1 \pm 8.2$ days. Neurological outcome was assessed by the GOS score after 6 months. The median GOS score was 5 (mean $3.92 \pm 1.34$ ) in the magnesium group and 4 (mean $3.45 \pm 1.46$ ) in the control group.

\section{Side effects}

Potential side effects of parenteral magnesium treatment are electrocardiographic changes, particularly bradycardic arrhythmias and a newly appearing atrioventricular block, hypocalcemic tetany and arterial hypotension. We found a tendency towards a slightly lower heart rate in magnesium-treated patients, several cases with facial flushing and one case with hypocalcemic tetany at serum levels above the target range which was successfully treated by dose-reduction. No further relevant side effects were observed, especially no life-threatening bradycardia and no hemodynamically relevant hypotension. In no case, therapy had to be stopped due to side effects of magnesium sulfate.

\section{Acquisition of Target Parameters}

In the entire patient collective, 613 native CTscans were obtained between admission and discharge. Of these, 484 were obtained at day three after admission or later. Following the study protocol, 414 PCTs were performed. 89 invasive angiographies (DSA) were performed due to suspected vasospasm in 53 of 107 patients. (Table 1)

\section{Neurological assessment}

61 of 107 patients (32 in the magnesium group, 29 in the control group) were amenable to neurological assessment throughout the hospital stay except for episodes in which they needed anesthesia or sedation (surgery, endovascular aneurysm treatment, reangiography for suspected vasospasm) In magnesium-treated patients, 9 episodes of DIND were registered. None was followed by secondary infarction within the following 3 days. In the control-group, 23 episodes of DIND were found. 9 were followed by secondary infarction $(p=0.31)$.

\section{Angiography}

Over all, 89 DSA were performed in 53 patients due to suspected vasospasm. In 27 patients, DSA was conducted more than once (Table 1). 40 digital subtraction angiographies (DSA) were performed in the magnesium group due to suspected vasospasm. 26 showed relevant arterial narrowing, 25 were treated by angioplasty, one by a local intraarterial nimodipine infusion. 2 of 26 were followed by secondary infarction within the following 3 days. In the control-group, 49 DSA were performed, 32 showed relevant arterial vasospasm, 27 were treated by angioplasty, 5 by intraarterial nimodipine infusion. 17 of 32 developed secondary infarction $(p=0.007)$.

\section{Transcranial Doppler Sonography (TCD)}

In the magnesium group, 114 TCD measurements showed elevated MFV. Of those, 7 were followed by secondary infarction. In the control-group, $135 \mathrm{TCD}$-measurements showed elevated MFV, 32 were followed by secondary infarction $(p=0.0009)$.

\section{Perfusion-CT (PCT)}

In all but 2 cases, Flow-Perfusion maps and Blood Volume maps showed defects which correlated with already demarcated infarction in native CT. In the magnesium group, 117 Time-To-Peak (TTP) maps showed abnormal findings. 10 of those were followed by secondary infarction within the following 3 days. In the control-group, 122 TTP maps showed pathological findings. 30 of those were followed by secondary infarction within the following 3 days $(p=0.006$ ). If differentiated by days after $\mathrm{SAH}$, the differences in occurrence of DIND, ultrasonographic vasospasm and PCT were not statistically significant due to the limited number of patients and events for each respective day.

\section{Discussion}

The data of the present analysis show that continuous intravenous treatment with magnesium sulfate significantly reduces the risk to develop secondary cerebral infarction in case of angiographic vasospasm, elevated flow velocities in TCD and pathological findings in PCT. Even in case of DIND, the risk of eventual infarction was reduced.

Promising results in experimental studies have raised high expectations that magnesium might be a valuable drug for the treatment of ischemic diseases of the brain, most of all in stroke patients. Several groups investigated

Table 1: Incidence of vasospasm and secondary infarction Incidence of vasospasm as determined by clinical examination (DIND), angiography (narrowing of vessel diameter $>50 \%$ ), TCD (MFV > $140 \mathrm{~cm} / \mathrm{s}$ ), and PCT (asymmetry or clear bilateral deficit). The incidence of DIND was reduced in magnesium-treated patients (32/54 patients in the magnesium group and 29/53 patients in the control group were neurologically assessable through the largest part of their hospital stay). There was no risk-reduction to develop arterial narrowing (DSA, TCD) or pathological perfusion patterns in PCT by magnesium-treatment. The risk to develop secondary infarction, however, was markedly reduced in magnesium-treated patients in conditions of arterial narrowing (DSA, TCD) and pathological findings in PCT. (Fisher Exact Test, DIND $=$ delayed ischemic neuro-

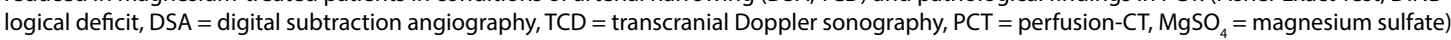

\begin{tabular}{|c|c|c|c|c|c|}
\hline & Number of patients/exams & Signs of Vasospasm & p-level & Secondary infarction & p-level \\
\hline DIND & $\begin{array}{l}\mathrm{MgSO}_{4} 32 \text { pats } \\
\text { Control } 29 \text { pats }\end{array}$ & $\begin{array}{c}\mathrm{MgSO}_{4} 9 / 32 \\
\text { Control 23/29 }\end{array}$ & $p=0.03$ & $\begin{array}{c}\mathrm{MgSO}_{4} \text { 0/9 } \\
\text { Control 9/23 }\end{array}$ & $p=0.167$ \\
\hline DSA & $\begin{array}{l}\mathrm{MgSO}_{4} 40 \text { exams } \\
\text { Control } 49 \text { exams }\end{array}$ & $\begin{array}{l}\mathrm{MgSO}_{4} 26 / 40 \\
\text { Control 32/49 }\end{array}$ & $p=1.00$ & $\begin{array}{l}\mathrm{MgSO}_{4} 2 / 26 \\
\text { Control 17/32 }\end{array}$ & $p=0.007$ \\
\hline $\mathrm{TCD}$ & $\begin{array}{l}\text { MgSO }_{4} 234 \text { exams } \\
\text { Control } 246 \text { exams }\end{array}$ & $\begin{array}{l}\mathrm{MgSO}_{4} 114 / 234 \\
\text { Control 135/246 }\end{array}$ & $p=0.48$ & $\begin{array}{c}\mathrm{MgSO}_{4} 7 / 114 \\
\text { Control 32/135 }\end{array}$ & $p=0.001$ \\
\hline $\mathrm{PCT}$ & $\begin{array}{l}\mathrm{MgSO}_{4} 210 \text { exams } \\
\text { Control } 196 \text { exams }\end{array}$ & $\begin{array}{l}\text { MgSO }_{4} 117 / 210 \\
\text { Control 122/196 }\end{array}$ & $p=0.51$ & $\begin{array}{l}\text { MgSO }_{4} 10 / 117 \\
\text { Control 30/122 }\end{array}$ & $p=0.006$ \\
\hline
\end{tabular}


the protective efficacy in experimental studies of permanent focal ischemia and consistently found reduced infarct volumes [1, 2, 20]. Likewise, a reduction of infarct volumes and improved neurological outcome was reported in animal models of temporary ischemia after intravenous administration of magnesium $[3,21]$. However, after promising results of small clinical trials $[5,6]$, a large multicenter trial failed to show improved outcome after embolic stroke (IMAGES - Intravenous Magnesium Efficacy in Stroke Trial [22]). The authors concluded from their data that one of the most important reasons for the failure of the IMAGES-trial may have been the mean delay of 7 hours from onset of symptoms to beginning of treatment as neuroprotective efficacy decreases the longer administration is delayed [23]

In $\mathrm{SAH}$, in turn, the prerequisites for a neuroprotective treatment are different. Delayed vasospasm of subarachnoid vessels appears in a high percentage of SAH patients within the first 2 weeks after SAH. Subarachnoid vessels become increasingly spastic and cerebral blood flow (CBF) may fall below ischemic thresholds [24]. This much-feared complication affects $20-30 \%$ of SAH patients and may result in cerebral infarction, permanent morbidity or death. Delayed cerebral vasospasm after SAH is self-limiting after several days or weeks and, therefore, resembles a form of transient focal ischemia. On the other hand, this course of events bears the opportunity to undertake neuroprotective measures prior to the onset of ischemia. In an animal model of temporary middle cerebral artery occlusion (MCAO), a dose-finding study has demonstrated that the intra- and postischemic maintainance of serum concentrations between 2.0 and $2.5 \mathrm{mmol} / \mathrm{l}$ offered the highest neuroprotection [4]. Consequently, this dose was used in our clinical trial. We previously reported the absence of relevant side effects during the continuous long-term administration of magnesium sulfate in this dose and the prevention of secondary infarction [14]. Recently, the topic of magnesium has been re-caught and in an intraoperative setting during aneurysm surgery, the CBFincreasing properties been demonstrated [25]. In addition, further experimental [26] and clinical data [27-29] has been published suggesting a dose-dependent neuroprotective effect of parenteral magnesium.

In the face of these new activities in the topic, this post-hoc analysis was conducted specifically focussing on the neuroprotective property under conditions of critical brain perfusion after aneurysmal SAH. Our analysis shows that the incidence of pathological findings in TCD and PCT - parameters of arterial narrowing - are not overwhelmingly different between the two trial-groups indicating that the effect of magnesium in this concentration as a vasodilator may be secondary. Our finding that only 9 of 32 patients who were neurologically assessable in the magnesium group developed DIND while 23 of 29 in the control group developed DIND suggests that the ischemic tolerance may be increased by magnesium treatment. The findings that magnesium treatment decreases the incidence of infarction, once DIND has occurred, points into the same direction. Elevated flow velocities in TCD measurements and pathological findings in PCT are surrogate parameters which indicate arterial narrowing and reduced brain perfusion, respectively. The incidence of secondary infarction following these conditions was significantly reduced as well. Our results strongly suggest a neuroprotective effect of magnesium treatment after $\mathrm{SAH}$.

The question arises why two large clinical trials have failed to show a beneficial effect in SAH-patients $[15,16]$. Wong et al. reported about 327 patients that were randomized to receive a daily dose of $80 \mathrm{mmol} / \mathrm{l} \mathrm{MgSO}_{4}$ or

Table 2: Randomized clinical studies investigating the therapeutic effect of intravenous magnesium to prevent delayed vasospasm and secondary ischemic events and to improve outcome after aneurysmal subarachnoid hemorrhage. The results are not unequivocal. The beneficial effect might depend on the dose-regimen and comedication.

\begin{tabular}{|c|c|c|c|c|}
\hline Author & Study setup & Treatment arms and comedication & Individuals & Results \\
\hline Luo et al., 1996 [9] & $\begin{array}{l}\text { Randomized, } \\
\text { patient-blinded }\end{array}$ & $\begin{array}{c}\mathrm{MgSO}_{4} \text { (approx. } 100-200 \mathrm{mmol} \text { per day for } 2-3 \\
\text { weeks) vs. placebo }\end{array}$ & 52 patients & $\begin{array}{l}\text { Significant reduction of secondary neurological } \\
\text { deterioration, reduction of delayed cerebral } \\
\text { infarction }\end{array}$ \\
\hline Veyna et al., 2002 [8] & $\begin{array}{l}\text { Randomized, } \\
\text { patient-blinded }\end{array}$ & $\begin{array}{l}\text { Nimodipine vs. nimodipine }+\mathrm{MgSO}_{4}(25 \mathrm{mmol} \\
+192 \mathrm{mmol} / \text { day for } 10 \text { days })\end{array}$ & 36 patients & $\begin{array}{l}\text { Safe use of magnesium. Non-significant trend to } \\
\text { improved clinical outcome }\end{array}$ \\
\hline $\begin{array}{l}\text { Van den Bergh et al., } \\
\qquad 2005[37]\end{array}$ & $\begin{array}{l}\text { Randomized, } \\
\text { double-blinded }\end{array}$ & $\begin{array}{l}\text { Nimodipine vs. nimodipine }+\mathrm{MgSO}_{4}(64 \mathrm{mmol} / \\
\text { day for } 14 \text { days })\end{array}$ & 283 patients & $\begin{array}{l}\text { Reduction of delayed cerebral ischemia and } \\
\text { trend to better neurological outcome }\end{array}$ \\
\hline $\begin{array}{l}\text { Schmid-Elsaesser et } \\
\quad \text { al., 2007 [12] }\end{array}$ & $\begin{array}{l}\text { Randomized, } \\
\text { double-blinded }\end{array}$ & $\begin{array}{c}\text { Nimodipine vs. } \mathrm{MgSO}_{4}(10 \mathrm{mg} / \mathrm{kg}+30 \mathrm{mg} / \mathrm{kg} / \\
\text { day for } 7 \text { days })\end{array}$ & 104 patients & $\begin{array}{l}\text { No significant difference between magnesium } \\
\text { and nimodipine }\end{array}$ \\
\hline Muroi et al., 2008 [10] & $\begin{array}{l}\text { Randomized, } \\
\text { patient-blinded }\end{array}$ & $\begin{array}{l}\text { Nimodipine vs. nimodipine }+\mathrm{MgSO}_{4}(16 \mathrm{mmol} \\
+64 \mathrm{mmol} / 24 \mathrm{~h} \text {, maximum serum concentration } \\
2.0 \mathrm{mmil} / \mathrm{l})\end{array}$ & 58 patients & $\begin{array}{c}\text { Trend to better clinical outcome after } 3 \text { and } 12 \\
\text { months. Treatment was stopped in } 16 \text { patients } \\
\text { due to hypotension, arrhythmias, respiratory } \\
\text { arrest and myocardial infarction }\end{array}$ \\
\hline Wong et al., 2010 [15] & $\begin{array}{l}\text { Randomized, } \\
\text { double blinded }\end{array}$ & $\begin{array}{l}\text { Nimodipine vs. nimodipine }+\mathrm{MgSO}_{4}(20 \mathrm{mmol} \\
+80 \mathrm{mmol} / \text { day for } 14 \text { days })\end{array}$ & 327 patients & No reduction of secondary ischemia or outcome \\
\hline $\begin{array}{l}\text { Westermaier et al., } \\
\quad 2010[14]\end{array}$ & $\begin{array}{l}\text { Randomized, } \\
\text { double-blinded }\end{array}$ & $\begin{array}{c}\mathrm{MgSO}_{4}(141 \pm 51 \mathrm{mmol} \text { - target serum level } 2.0- \\
2.5 \mathrm{mmol} / \mathrm{l}) \text { vs. placebo }\end{array}$ & 107 patients & $\begin{array}{c}\text { Significant reduction of secondary infarction } \\
\text { and ultrasonographic/angiographic vasospasm. } \\
\text { Non-significant reduction of neurological } \\
\text { outcome and mortality }\end{array}$ \\
\hline Mees et al., 2012 [16] & $\begin{array}{l}\text { Randomized, } \\
\text { double-blinded }\end{array}$ & $\begin{array}{l}\text { Nimodipine vs. nimodipine }+\mathrm{MgSO}_{4}(64 \mathrm{mmol} / \\
\text { day })\end{array}$ & 1207 patients & No improvement of clinical outcome \\
\hline
\end{tabular}


placebo. The authors reported no significant benefit of magnesium-treatment regarding clinical outcome after 6 months or clinical vasospasm [15]. The results of the largest clinical trial have been published by Mees and coworkers. In this multicenter study, 1,204 patients with aneurysmal SAH were enrolled and assigned to one of two study arms to either receive $64 \mathrm{mmol} \mathrm{MgSO}_{4}$ per day or serve as controls. The administration of $\mathrm{MgSO}_{4}$ did not improve clinical outcome assessed 3 months after SAH [16].

This data requires a critical analysis. In both trials, all patients - treatment and control group - were co-treated with nimodipine. This pyrrolopyrimidine-type calcium antagonist, has been intensively tested in various clinical studies in the 1980s and 1990s. Analyzing the pooled data for nimodipine trials, a Cochrane review revealed an advantage of nimodipine treatment, so that this treatment is routinely used in many centers. The review concludes, however, that the evidence for nimodipine was not beyond any doubt since the benefit of treatment is largely determined by one trial $[30,31]$. The magnesium doses used in both trials were markedly lower than in our study in which $140 \pm 51 \mathrm{mmol} / \mathrm{d}$ were administered to maintain the target serum parameters. In fact, dose regimens were used in those trials that had previously failed to prove a neuroprotective effect in stroke patients [32] and were neither tested in experimental settings nor in earlier clinical trials before launching the randomized trial. It is well known that magnesium has clear dose dependent effects [33]. New experimental data emphasizes that a neuroprotective action may not be exerted below a certain concentration [26]. Therefore, plasma concentrations need to be high enough. Our study used higher doses than other trials (Table 2) and - although it is a monocenter study - is the only one to investigate a dosing schedule that was a) controlled by serum levels, and b) tested for its neuroprotective efficacy in a preclinical experimental setting.

Our serum-level targeted dose-regimen was chosen on the basis of previous experimental studies that offered the highest neuroprotective effect in a model of temporary cerebral ischemia. On the other side, the cotreatment with nimodipine and magnesium is a simultaneous treatment with two calcium antagonists offering similar modes of action. Again, experimental studies have to be looked at and suggest that the neuroprotective effect of nimodipine may not be enhanced by combination therapies [34]. Schmid-Elsaesser et al. compared nimodipine treatment to magnesium treatment and found no marked and significant difference in the incidence of vasospasm and clinical outcome [12]

In the present study, 107 patients were randomized to either receive a placebo infusion or to receive a variable dose of intravenous $\mathrm{MgSO}_{4}$ in order to maintain serum concentrations of $2.0-2.5 \mathrm{mmol} / \mathrm{l}$ for 10 days or - if there was clinical, angiographic and/or ultrasonographic vasospasm - until the signs of vasospasm had disappeared or to receive a placebo infusion without other calcium antagonists [14].

The fact that it resembles an incidentrelated rather than a patient-related analysis is a limitation of this study. A patient-related analysis has been reported previously [14]. It was, therefore, our purpose to investigate the tissue-protective effect of the compound once a sign of critical brain perfusion has appeared. The incidence-related assessment takes into account that a patient may have more than one episode of critical brain perfusion in the course of the disease and may react in a different way each time. However, it disregards that there may be a different degree of ischemic tolerance in each patient which may influence the risk of infarction and neurological recovery and make the analysis less precise. The choice of parameters that possibly indicate critical brain perfusion is another limitation of this analysis. Apart from clinical deterioration (DIND), all other parameters of this study indicating threatened brain perfusion (TCD, PCT, DSA) are surrogate parameters. We did not use absolute measures of CBF like thermodilution or Xenon$\mathrm{CT}$ or single photon emission tomography in the daily routine, nor was it part of the study protocol. Although it is known today, that vasospasm is not the sole determinant of delayed ischemic deficits and infarction, it is widely accepted that reduced brain perfusion is a clear risk factor $[35,36]$. All parameters used in this analysis are validated to indicate arterial narrowing or altered flow and tissue supply and perfusion at risk. Therefore, the results of this analysis suggest that, under these circumstances and if administered in an appropriate dose, magnesium can be neuroprotective in conditions of critical brain perfusion.

\section{Conflict of Interest}

None of the authors has a conflict of interest to declare.

\section{Funding}

This publication was funded by the German Research Foundation (DFG) and the University of Wuerzburg in the funding programme Open Access Publishing.

References

[1] Izumi Y, Roussel S, Pinard E, Seylaz J, Reduction of infarct volume by magnesium after middle cerebral artery occlusion in rats, J Cereb Blood Flow Metab 1991, 11, 1025-1030.

[2] Lee EJ, Ayoub IA, Harris FB, Hassan M, Ogilvy CS, Maynard Kl, Mexiletine and magnesium independently, but not combined, protect against permanent focal cerebral ischemia in Wistar rats, $J$ Neurosci Res 1999, 58, 442-448.
[3] Marinov MB, Harbaugh KS, Hoopes PJ, Pikus HJ, Harbaugh RE, Neuroprotective effects of preischemia intraarterial magnesium sulfate in reversible focal cerebral ischemia, J Neurosurg 1996, 85, 117-124.

[4] Westermaier T, Zausinger S, Baethmann A, Schmid-Elsaesser R, Dose finding study of intravenous magnesium sulphate in transient focal cerebral ischemia in rats, Acta Neurochir (Wien) 2005, 147, 525-532. 
[5] Wester PO, Asplund K, Eriksson S, Hagg E, Lithner F, Strand T, Infusion of magnesium in patients with acute brain infarction, Acta Neurol Scand 1984, 70, 143.

[6] Muir KW, Lees KR, A randomized, double-blind, placebo-controlled pilot trial of intravenous magnesium sulfate in acute stroke, Stroke 1995, 26, 1183-1188.

[7] Chia RY, Hughes RS, Morgan MK, Magnesium: a useful adjunct in the prevention of cerebral vasospasm following aneurysmal subarachnoid haemorrhage, J Clin Neurosci 2002, 9, 279-281.

[8] Veyna RS, Seyfried D, Burke DG, Zimmerman C, Mlynarek M, Nichols $V$ et al., Magnesium sulfate therapy after aneurysmal subarachnoid hemorrhage, J Neurosurg 2002, 96, 510-514.

[9] Luo W, Qiu S, Ma W, Clinical study of magnesium sulphate on delayed cerebral vasospasmafter subarachnoid haemorrhage, Journal of Clinical Neurology 1996, 9, 244-245.

[10] Muroi C, Terzic A, Fortunati M, Yonekawa Y, Keller E, Magnesium sulfate in the management of patients with aneurysmal subarachnoid hemorrhage: a randomized, placebo-controlled, dose-adapted trial, Surg Neurol 2008, 69, 33-39.

[11] Prevedello DM, Cordeiro JG, de Morais AL, Saucedo NSJ, Chen IB, Araujo JC, Magnesium sulfate: role as possible attenuating factor in vasospasm morbidity, Surg Neurol 2006, 65, 14-20.

[12] Schmid-Elsaesser R, Kunz $M$, Zausinger $S$, Prueckner $S$, Briegel $\mathrm{J}$, Steiger $\mathrm{HJ}$, Intravenous magnesium versus nimodipine in the treatment of patients with aneurysmal subarachnoid hemorrhage: a randomized study, Neurosurgery 2006, 58, 1054-1065.

[13] Stippler M, Crago E, Levy El, Kerr ME, Yonas H, Horowitz MB et al., Magnesium infusion for vasospasm prophylaxis after subarachnoid hemorrhage, J Neurosurg 2006, 105, 723-729.

[14] Westermaier T, Stetter C, Vince GH, Pham M, Tejon JP, Eriskat J et al., Prophylactic intravenous magnesium sulfate for treatment of aneurysmal subarachnoid hemorrhage: a randomized, placebocontrolled, clinical study, Crit Care Med 2010, 38, 1284-1290.

[15] Wong GK, Poon WS, Chan MT, Boet R, Gin T, Ng SC et al., Intravenous magnesium sulphate for aneurysmal subarachnoid hemorrhage (IMASH): a randomized, double-blinded, placebo-controlled, multicenter phase III trial, Stroke 2010, 41, 921-926.

[16] Mees SM, Algra A, Vandertop WP, van Kooten F, Kuijsten HA, Boiten J et al., Magnesium for aneurysmal subarachnoid haemorrhage (MASH-2): a randomised placebo-controlled trial, Lancet 2012.

[17] Kunze E, Stetter C, Willner N, Koehler S, Kilgenstein C, Ernestus RI et al., Effects of Fluid Treatment With Hydroxyethyl Starch on Renal Function in Patients With Aneurysmal Subarachnoid Hemorrhage, J Neurosurg Anesthesiol 2016, 28, 187-194.

[18] Pham M, Johnson A, Bartsch AJ, Lindner C, Mullges W, Roosen K et al., $\mathrm{CT}$ perfusion predicts secondary cerebral infarction after aneurysmal subarachnoid hemorrhage, Neurology 2007, 69, 762-765.

[19] von Kummer R, Bourquain H, Bastianello S, Bozzao L, Manelfe C, Meier $D$ et al., Early prediction of irreversible brain damage after ischemic stroke at CT, Radiology 2001, 219, 95-100.

[20] Chung SY, Lin JY, Lin MC, Liu HM, Wang MF, Cheng FC, Synergistic efficacy of magnesium sulfate and FK506 on cerebral ischemia- induced infarct volume in gerbil, Med Sci Monit 2004, 10, BR105BR108.

[21] Schmid-Elsaesser R, Zausinger S, Hungerhuber E, Baethmann A, Reulen $\mathrm{HJ}$, Neuroprotective effects of combination therapy with tirilazad and magnesium in rats subjected to reversible focal cerebral ischemia, Neurosurgery 1999, 44, 163-171.

[22] Muir KW, Lees KR, Ford I, Davis S, Magnesium for acute stroke (Intravenous Magnesium Efficacy in Stroke trial): randomised controlled trial, Lancet 2004, 363, 439-445.

[23] Yang Y, Li Q, Ahmad F, Shuaib A, Survival and histological evaluation of therapeutic window of post-ischemia treatment with magnesium sulfate in embolic stroke model of rat, Neurosci Lett 2000, 285, 119122.

[24] Jones TH, Morawetz RB, Crowell RM, Marcoux FW, FitzGibbon SJ, DeGirolami $U$ et al., Thresholds of focal cerebral ischemia in awake monkeys, J Neurosurg 1981, 54, 773-782.

[25] Sommer B, Weidinger CS, Wolf D, Buchfelder M, Schmitt $H$, Intraoperative continuous cerebral microcirculation measurement in patients with aneurysmal subarachnoid hemorrhage: preliminary data on the early administration of magnesium sulfate, BMC Anesthesiol 2017, 17, 143-0435.

[26] Itoh K, Maki T, Shindo A, Egawa N, Liang AC, Itoh N et al., Magnesium sulfate protects oligodendrocyte lineage cells in a rat cell-culture model of hypoxic-ischemic injury, Neurosci Res 2016, 106, 66-69.

[27] Pearce A, Lockwood C, van den Heuvel C, Pearce J, The use of therapeutic magnesium for neuroprotection during global cerebral ischemia associated with cardiac arrest and cardiac surgery in adults: a systematic review, JBI Database System Rev Implement Rep 2017, 15, 86-118.

[28] Zhang LW, Warrington JP, Magnesium Sulfate Prevents Placental Ischemia-Induced Increases in Brain Water Content and Cerebrospinal Fluid Cytokines in Pregnant Rats, Front Neurosci 2016, 10, 561.

[29] Chakkarapani E, Chau V, Poskitt KJ, Synnes A, Kwan E, Roland E et al., Low plasma magnesium is associated with impaired brain metabolism in neonates with hypoxic-ischaemic encephalopathy, Acta Paediatr 2016, 105, 1067-1073.

[30] Pickard JD, Murray GD, Illingworth R, Shaw MD, Teasdale GM, Foy PM et al., Effect of oral nimodipine on cerebral infarction and outcome after subarachnoid haemorrhage: British aneurysm nimodipine trial, BMJ 1989, 298, 636-642.

[31] Dorhout MS, Rinkel GJ, Feigin VL, Algra A, van den Bergh WM, Vermeulen $\mathrm{M}$ et al., Calcium antagonists for aneurysmal subarachnoid haemorrhage, Cochrane Database Syst Rev 2007, CD000277.

[32] Dorhout MS, Algra A, Wong GK, Poon WS, Bradford CM, Saver JL et al., Early Magnesium Treatment After Aneurysmal Subarachnoid Hemorrhage: Individual Patient Data Meta-Analysis, Stroke 2015, 46, 3190-3193.

[33] Mohr K, Therapeutic drugs. Magnesium, Dtsch Med Wochenschr 1994, 119, 1669-1670.

[34] Zausinger S, Westermaier T, Plesnila N, Steiger HJ, Schmid-Elsaesser R, Neuroprotection in transient focal cerebral ischemia by combination drug therapy and mild hypothermia: comparison with customary 
therapeutic regimen, Stroke 2003, 34, 1526-1532.

[35] Pluta RM, Hansen-Schwartz J, Dreier J, Vajkoczy P, Macdonald RL, Nishizawa $S$ et al., Cerebral vasospasm following subarachnoid hemorrhage: time for a new world of thought, Neurol Res 2009, 31, 151-158.

[36] Frontera JA, Fernandez A, Schmidt JM, Claassen J, Wartenberg KE, Badjatia $\mathrm{N}$ et al., Defining vasospasm after subarachnoid hemorrhage: what is the most clinically relevant definition?, Stroke $2009,40,1963-$ 1968.

[37] van den Bergh WM, Algra A, van Kooten F, Dirven CM, van Gijn J, Vermeulen $M$ et al., Magnesium sulfate in aneurysmal subarachnoid hemorrhage: a randomized controlled trial, Stroke 2005, 36, 10111015. 